\title{
Professional learning and development in early childhood education: A shifting landscape of policies and practice
}

\author{
Sue Cherrington \\ Institute for Early Childhood Studies, Faculty of Education, Victoria University of Wellington
}

This article traces shifts in the New Zealand early childhood professional, regulatory and policy landscape, and examines how these shifts create challenges and opportunities for early childhood teachers' engagement in professional learning and development (PLD). It presents current understandings about effective PLD for teachers in the early childhood and wider education literature before arguing that professional learning communities offer promising opportunities to support early childhood teachers' engagement in effective PLD in a shifting policy and practice landscape.

Keywords: Early childhood education; professional learning and development; professional learning communities; communities of learners; ECE policy

\section{Introduction}

The New Zealand early childhood education (ECE) sector has experienced major policy and regulatory shifts in the last decade that have had significant impacts on the sector. Substantial increases in the number of qualified and registered teachers in the teacher-led sector ${ }^{1}$ over the past 15 years (Education Counts, 2017a) have combined with these policy changes to impact the professional learning and development (PLD) landscape within the sector. This article begins by outlining the current policy and professional contexts within which early childhood (EC) teachers' professional learning is located and how these issues combine to challenge teachers' engagement in PLD. It then examines insights from the education literature on effective PLD to consider strategies to support EC teachers' engagement in effective PLD in a shifting policy and practice landscape.

Three regulatory agencies are influential in the EC professional learning landscape: the Ministry of Education (MOE), the Education Review Office (ERO) and, for teacher-led services, the Education Council of New Zealand (ECNZ). Collectively, these agencies express clear expectations that EC practitioners are engaged in ongoing PLD and that ECE services have responsibilities to support such engagement. For example, the Education (Early Childhood) regulation 47 (e) "requires every licensed service provider ... to ensure that ... all reasonable steps are taken to provide staff employed or engaged in the service with adequate

\footnotetext{
1 Within the NZ ECE context, teacher-led services encompassing education and care centres, kindergartens, home-based networks, and hospital-based services are required to meet regulated proportions of qualified and registered teachers. Other ECE service types, including playcentres and Kohanga Reo, have separate staffing and qualification regulations.
} 
professional support, professional development opportunities, and resources" (MOE, 2008a, p. 31).

Alongside this regulation the MOE's licensing criteria for centre-based ECE services require management to make provision for staff engagement in professional development as part of human resource management practices (GMA7, MOE, 2008b) and budget for professional development costs as part of their financial requirements (GMA9, MOE, 2008b). Whilst the licensing criteria do not include explicit expectations directed at practitioners to engage in ongoing PLD, the supporting guidance material includes this statement in relation to adults' knowledge:

The early childhood education knowledge-base is constantly being revised and developed. Professional learning helps us to keep up-to-date with these changes. Participating in professional development opportunities (formal and informal) and professional reading helps us to continuously build on our understanding. Educators should take opportunities to discuss and debate ideas and theories, and identify meaningful ways to put their new knowledge into practice. (MOE, 2008b)

ERO's (2014) framework for EC reviews, He Pou Tātaki, also addresses engagement in PLD. Each pou in the framework - representing inter-related factors contributing towards quality ECE provision - references professional learning opportunities and activities as elements supporting quality practices. Self-review templates, completed by umbrella organisations and services prior to reviews, include a specific focus on professional learning. At the service level, questions focus on how services decide on PLD priorities and the impact of recent PLD on their ability to promote positive outcomes for all children whilst for umbrella organisations, the focus is on how they determine and provide for their services' PLD needs and their current PLD focus.

The emphasis on ongoing PLD is also evident in two $\operatorname{ERO}(2010,2016)$ national reports on quality in New Zealand ECE and the early learning curriculum, respectively, that both highlighted the important role of PLD in addressing inconsistent quality of practice across the sector. The 2016 report noted that:

Leaders and teachers need to increasingly engage in ongoing professional learning, and develop a reflective culture that refers to current research in questioning and evaluating their practice. Ongoing professional learning is a vital tool for teachers to strengthen their own pedagogy and capability. (p. 45)

The third key agency in this space, the ECNZ, is explicit in its expectation that registered teachers engage in ongoing professional learning in order to maintain their practising certificates. Criterion four of the current Practising Teacher Criteria requires that teachers "demonstrate commitment to ongoing professional learning and development of personal professional practice" whilst criterion twelve alludes to practices integral to professional learning when it states that teachers will "use critical inquiry and problem-solving effectively in their professional practice" (ECNZ, 2016). Both criteria are supported by indicators that further reinforce the Council's expectations about teachers engaging in ongoing professional learning. The Council's new Standards for the Profession, to be fully implemented from January 2018, continue this explicit expectation in the second standard: 
Professional learning

Use critical inquiry, collaborative problemsolving and professional learning to improve professional capability to impact on the learning and achievement of all learners. (ECNZ, 2017, p. 40)

So, taken together, there is a clear set of expectations within the policy and regulatory context that EC practitioners will engage in ongoing professional learning. But how does that happen? The next section of this article explores policy shifts in the provision of PLD programmes for EC practitioners over the past two decades that have influenced PLD engagement.

\section{Policy shifts in ECE professional learning and development provision}

Since the introduction of the EC curriculum, Te Whāriki, in 1996, the MOE has played a key role in providing funding for EC PLD programmes, based on its broader policy priorities. From 1997 until 2010, the MOE's PLD funding was based on each EC service accessing in-depth PLD (either whole-centre or cluster) every three years. Such PLD focused on strengthening practitioners' understanding and use of curriculum (MOE, 1996), assessment (MOE, 2004, 2009), and self-review (MOE, 1999, 2006) resources. The comprehensive coverage provided by MOE-funded contracts, including participation funding to help cover costs such as relievers, resulted in many EC services making little or no provision for self-funded PLD within their annual budgets.

However, significant policy shifts occurred in 2010 with the introduction of a targeted approach to MOE-funded PLD provision under the Strengthening Early Learning Opportunities (SELO) initiative and a reduction in overall ECE PLD budgets from \$11 million per annum for the 2007-08 years (MOE, 2007) to $\$ 5.5$ million per annum for the 2010-13 years (MOE, 2010). Under the SELO initiative, "ECE professional development investment has been targeted towards services with the greatest chance of meeting" the goal of improved ECE participation among Māori and Pasifika children and children from low socio-economic families (MOE, 2017a). Limited funding has also been available for small national programmes focused on infants and toddlers, mathematics, early literacy, Māori leadership, Pasifika leadership, EC leadership, and Whakapiki i te reo, with a strong emphasis on effectively engaging priority families and children.

The recent launch of the revised EC curriculum, Te Whāriki 2017 (MOE, 2017b), has been accompanied by a \$4 million PLD package to support its implementation. The PLD available through this funding has a strong emphasis on workshops and web-based resources, including webinars, and some limited opportunities for services to engage in facilitated curriculum inquiries and communities of practice (MOE, 2017b).

\section{Communities of Learning / Kāhui Ako}

Changes in Ministry PLD policy have not been limited to ECE. Indeed, significant changes to the conceptualisation and structure of PLD for the compulsory schooling sector followed the release of the MOE Professional Development Advisory Group's (2014) report. The Investing in Educational Success initiative, introduced in 2014, will provide for up to 250 Community of Learning (COL | Kāhui Ako) clusters of schools (210 as at August 2017) and also provide funding for teachers to develop innovative teaching practices through the Teacher-led Innovation Fund (MOE, 2016a). 
Whilst both the COL | Kāhui Ako initiative and the new approach to accrediting PLD facilitators were not designed with the ECE sector in mind, the MOE's Early Childhood Advisory Committee has since provided advice on how ECE services could be integrated within COLs | Kāhui Ako, particularly where there are large numbers of contributing ECE services (MOE, 2016c). With 279 ECE services currently participating in COLs | Kāhui Ako, these changes to the schooling PLD system are increasingly influencing the future direction of early childhood PLD policy.

\section{A changing early childhood workforce}

Alongside the EC PLD policy shifts outlined above, engagement opportunities in PLD have been influenced by significant growth in the number of qualified and registered teachers since the launch in 2002 of the EC strategic plan, Nga huarahi arataki: Pathways to the future (MOE, 2002). In addition to the plan's strategy to increase the numbers of registered teachers, two further factors have driven the growth in qualified teacher numbers: firstly, a $50 \%$ increase in teacher-led EC services between 2002 and 2016, notably in the home-based and education and care sectors; and secondly, shifts in license type from sessional to full-day, particularly in the kindergarten sector, resulting in an almost $97 \%$ decrease in the number of sessional centres from 717 in 2002 to 22 in 2016 (Education Counts, 2017b).

During the period from 2002 to 2014 there has been an overall increase of 13,047 (106.62\%) staff within teacher-led services, with 12,904 (216.76\%) more qualified teachers in 2014 than there were in 2002. Proportionally, qualified teachers have risen from less than half $(48.64 \% ; \mathrm{N}=5953)$ to nearly three-quarters $(74.58 \% ; \mathrm{N}=18857)$ of the teacher-led workforce in this period (Education Counts, 2017a). Such increases in the sector result in increased expectations of, and demand for involvement in PLD, particularly for teachers required to maintain their practising certificates.

Despite these changes to the EC teacher workforce, little is known about how EC practitioners make decisions about their engagement in PLD, echoing international findings. In the Australian context, Brownlee and colleagues (2015) argue that despite increases in the range of PLD opportunities available to practitioners, there is "no systematic monitoring of the quality of the options on offer" (p. 411) and little is known about how EC leaders make decisions about PLD engagement. In New Zealand, Cherrington and Wansbrough's (2007) national evaluation of EC PLD found that engagement in PLD was influenced by the extent to which the service (or its umbrella organisation) actively sought PLD tailored to its needs, or waited for providers to approach them. Using the latter strategy meant that some services risked missing out on in-depth PLD. Furthermore, teachers often made spontaneous decisions to engage in PLD in response to advertised opportunities, with such decisions not always related to their identified appraisal needs (Cherrington \& Wansbrough, 2007).

Similarly, data concerning PLD that teachers engage with beyond MOE-funded programmes are limited. Cherrington and Wansbrough (2007) found services engaged in a range of non-MOE funded PLD, primarily short courses or conferences, with three factors influencing participation: the topic or focus of the activity; quality of speakers; and opportunities for networking. Today, most non-MOE funded PLD is provided through inhouse programmes offered by umbrella organisations, short one-off seminars and workshops offered by private providers, or conferences. External PLD is typically advertised in the Education Gazette; a scan of gazettes over the past year reveals most offerings are one-off 
symposiums, workshops and short courses over a range of topics, including managementrelated issues. Occasional advertisements for regional or national conferences (both ECE and general education), fellowships and tertiary-level study are also evident. Thus, outside of the MOE's targeted PLD programmes and the limited, albeit increasing, participation in COL I Kāhui Ako, few opportunities currently exist for teachers to engage in PLD beyond those offered by umbrella organisations.

Taken together, three key aspects - greater expectations that practitioners engage in ongoing PLD, significantly increased numbers of qualified teachers required to demonstrate such engagement, and changes to MOE-funded PLD - have created a seismic shift in the EC PLD landscape and pose major challenges for the sector, at both a systems level and within local contexts. At the systems level, challenges exist in ensuring equitable access to high quality PLD, particularly for services located in provincial and rural areas (Cherrington \& Wansbrough, 2007), that meets the diverse needs of practitioners whose qualifications and experiences continue to be varied. Challenges at the local level include building the capacity of practitioners and services to identify appropriate approaches for addressing their PLD needs and how best to resource these, including through internal and external supports, in a changing PLD landscape. These challenges are exacerbated by the increasing financial pressures faced by services following cuts in government funding in 2010 that removed the 80-100\% qualified staff funding band and an ongoing freeze of the "per child" hourly funding rates; almost three-quarters of centres report "staff professional development and learning had been affected" by these changes (NZEI Te Riu Roa, 2016). Across both the system level and within local contexts, the core challenge remains ensuring that all EC practitioners engage in effective PLD that impacts positively on their practice, on children's learning, and on relationships with whānau.

Whilst addressing these challenges requires a return to funding rates that support quality ECE practice, they also demand shifts in thinking about how the sector approaches and engages in PLD. Doing so opens up possibilities for practitioner- and research-driven professional learning capable of transforming practice. In the next section, I argue how the sector, at both the systems and local levels, might meet this challenge by scoping out what is known about effective PLD in educational contexts before discussing possibilities for EC professional learning and the system and local supports needed to enact such PLD effectively.

\section{Effective professional learning and development}

Extensive literature exists focused on approaches to PLD within both the EC and wider education sectors that contribute to improving teacher practice and outcomes for learners. Whilst much of the schooling PLD literature provides helpful insights into approaches that may also be effective in EC contexts, a degree of caution is required given the unique characteristics of the EC sector. As Edwards and Nuttall (2009) note, "the nature, processes, and purposes of professional learning are highly dependent upon specific social, cultural, economic, historical and interpersonal contexts" (p. 2). Waters and Payler (2015) highlight that, internationally, EC PLD must take account of differing qualification levels amongst staff who may work in "a large variety of provider-types, bringing challenges in terms of costs, regulatory systems and organisational networks" (p. 162). Although a unified EC regulatory framework exists within New Zealand, the challenges of multiple service types and organisational networks, and a mix of qualified, in-training and unqualified staff exist here. 
Furthermore, staff turnover in EC services (Education Counts, 2017a; Gomez, Kagan, \& Fox, 2015) creates additional challenges for engagement in ongoing PLD.

Avalos's (2011) review of research into teacher professional development noted that different forms of PLD will not be relevant for all teachers but that there has been a significant move away from "the traditional in-service teacher training (INSET) model" (p. 17). Such traditional models tend to emphasise PLD undertaken away from teachers' workplaces and disconnected to their practices, where participants receive content delivered by experts (Barber, Cohrssen, \& Church, 2014). In contrast, the construct of professional learning positions teachers as life-long learners, takes account of teachers' experiences, and is located in or related directly to the contexts within which they work. Such PLD is grounded in situative approaches to learning (e.g., Greeno, 1997; Greeno and colleagues, 1998; Lave \& Wenger, 1991) where learning is viewed as located within, and shaped by the social contexts within which it is situated, including the activities engaged in, and the tools and processes used. Following their review of research into effective professional learning, Opfer and Pedder (2011) highlight situative learning elements when they report that:

Teachers learn most effectively when activities require them to engage with material of practice ..., when activity is school-based and integrated into the daily work of teachers ..., and when the pedagogy of PD is active and requires teachers to learn in ways that reflect how they should teach pupils. Teachers are less likely to change practice as a result of learning activities that occur via presentation and the memorizing of new knowledge. (p. 385)

The eight characteristics of effective professional development identified in Mitchell and Cubey's (2003) EC Best Evidence Synthesis also collectively align with situative approaches to PLD, highlighting the importance of teachers being "involved in investigating pedagogy within their own early childhood settings" and "analys[ing] data from their own settings" (p. xi).

\section{Collaborative approaches to professional learning and development}

Situative approaches underpin the PLD that groups or communities of teachers are engaged in when they participate in collaborative inquiry into their own teaching and its impact on learners. Such groups are variously described as communities of learners (MOE, 2017c), collaborative teacher inquiry teams (Ermeling, 2010), communities of inquiry (Kintz, Lane, Gotwals, \& Cisterna, 2015), and professional learning communities (PLC) (Hipp \& Huffman, 2010), or may be groups that engage in practitioner inquiry (Newman \& Mowbray, 2012).

Of these, arguably most research has been undertaken into PLCs defined by Hipp and Huffman (2010) as "professional educators working collectively and purposefully to create and sustain a culture of learning for all students and adults" (p. 12). Similarly, Stoll and Louis (2007) suggest that in PLCs, the "focus is not just on individual teachers' learning but on (1) professional learning; (2) within the context of a cohesive group; (3) that focuses on collective knowledge; and (4) occurs within an ethic of interpersonal caring that permeates the life of teachers, students and school leaders" (p. 3). Being able to participate within teacher communities such as PLCs is, according to Borko, Jacobs, and Koellner (2010), "an essential component of high-quality PD" (p. 550). Teacher learning in such communities becomes a collective, rather than an individual endeavour (Opfer \& Pedder, 2011). 


\section{Developing effective learning communities}

Grossman, Wineburg, and Woolworth's (2001) oft-repeated caution that a group of teachers in a room does not equal a learning community remains relevant today. Regardless of how they are labelled, several characteristics of effective learning communities are evident, supported by a number of relational and structural conditions. A recurrent theme throughout the literature is the need for members to have a shared vision and values (DuFour \& Eaker, 1998; Hipp \& Huffman, 2010) that enable participants to be clear about the purpose of their community (Earley \& Porritt, 2009; Kintz et al., 2015), to take ownership of their PLD and to focus on student outcomes (Earley \& Porritt, 2009).

Effective communities focus on continuous improvement and are oriented towards action, experimentation and results (DuFour \& Eaker, 1998). Using data on student learning to understand "problems of practice" (Horn \& Little, 2010, p. 189) and to measure the impact of shifts in teacher practice on students' learning is a core activity. Whilst these data can include evidence from a wide range of sources to give insights into students' social and dispositional development alongside their scholastic achievements (Owen, 2015), teachers often require support to analyse, understand and engage in learning conversations about such data (Earl \& Timperley, 2008).

Working collaboratively with others is at the heart of teachers' engagement within a learning community. Collaborative activities support changes in teachers' beliefs and practices (Owen, 2015), scaffold participants' learning and understandings, and help to maintain motivation and commitment (Newman \& Mowbray, 2012). However, developing collaborative learning communities requires attention to the nature of collaboration expected, as summed up by Opfer and Pedder (2011):

The intensity of collaboration becomes an important determinant - too much collaboration and learning are stifling, too little collaboration and teacher isolation inhibit growth, just enough collaboration and teachers receive the stimulation and support from colleagues necessary for change. (p. 386)

Relational and structural supports are required to develop sustainable learning communities as these are "the glue that holds all other dimensions together" (Hipp \& Huffman, 2010, p. 19). Arguably the most important is shared and supportive leadership (Hipp \& Huffman, 2010) given its influence on other relational and structural conditions. Positional leaders play an important enabling role, whether directly involved in the community's work or not, in helping to create a learning culture whereby teachers are encouraged to examine, critique and explore alternative practices, and in optimising the provision of structural supports. Where supportive positional leadership exists, shifts in practice are more likely to be embedded and sustained (Thornton \& Cherrington, 2014). Distributed leadership may also be developed within learning communities as teachers take on new roles and develop leadership capacity, both within the community and within their workplace settings (Newman \& Mowbray, 2012).

Participation in a collaborative learning community involves teachers de-privatising their practices (McLaughlin \& Talbert, 2006) and engaging in supportive but challenging conversations (Borko, 2004) and, thus, developing relational trust and managing power dynamics are key relational aspects underpinning effective learning communities (Stoll, Bolam, McMahon, Wallace, \& Thomas, 2006). Supportive structural conditions include what Ermeling (2010) described as "stable settings" (p. 387) - the time and space for groups to 
meet together during their workday - with sustained and intensive PLD identified as more effective for teachers' learning (Guskey, 2000; Opfer \& Pedder, 2011). Studies have noted the challenges faced by EC services in creating time and space for teachers to engage in sustained inquiry into their teaching (Cherrington \& Thornton, 2015; Newman \& Mowbray, 2012), particularly for those working within full-day programmes.

\section{Looking forward: Developing learning communities in early childhood education}

In this final section, I argue that PLCs have potential for supporting sustained EC teacher learning, particularly given increased demand for PLD amongst qualified, registered teachers, the emerging engagement of ECE within COL | Kāhui Ako, and the transference of responsibility for government-funded PLD for teachers to the ECNZ from 2019. I outline what I believe needs to occur, at both a system level and within local EC contexts, in order to enable the development of effective PLCs within the New Zealand EC sector.

Thornton and Wansbrough (2012) highlighted reasons why EC teachers should work towards developing effective PLCs: firstly, given that the ECNZ's requirements apply to EC teachers alongside their primary and secondary sector colleagues, it is important that EC teachers engage in ongoing professional learning within or across their services; secondly, EC teachers are expected to work collaboratively within teams and with parents and whānau to ensure that children's learning needs are supported; and; thirdly, working in a close physical space can make it challenging for EC teachers to engage in critical discussions of the type that Earl and Timperley (2008) advocate.

Recent research with my colleague, Kate Thornton, investigated the development of four PLCs in EC (see Cherrington \& Thornton, 2015, for further detail). Both structural and relational aspects impacted the development of these PLCs; individual participants coped with structural changes including changes in their licensing conditions and significant staff turnover. Beyond these centre-specific issues, each PLC was unable to meet during work hours; following an introductory seminar held on a Saturday, PLC meetings were scheduled for the early evening to enable members to participate after centre programmes had finished for the day. The development of trust, quality of leadership and addressing issues of power and group dynamics amongst participants were key relational elements influencing the extent to which each PLC was able to engage in open discussion and reflection on their practices. For example, positional power (Dana \& Yendol-Hoppey, 2008) was used positively by leaders within one PLC to surface and address a team member's unwillingness to critique her own practice and be part of the centre's developing collective culture. In another PLC, however, the positional leader's disengagement in the project contributed to a lack of progress by the PLC and little sustained change in practice (Thornton \& Cherrington, 2014).

Despite these challenges, we found that the model of PLCs has potential for improving teachers' professional practices and for enhancing children's learning within the ECE sector. Whilst each PLC made progress with their action research investigations, a timeframe longer than that available within our pilot study was required to develop each group into a selfsustaining PLC. The need for extended timeframes to enable PLCs to become self-sustaining is an emerging finding in our current three-year project, in line with Hipp, Huffman, Pankake, and Olivier's (2008) research in the schooling sector.

Developing sustainable PLCs in the EC sector requires shifts in how PLD is conceptualised at both the local level and at a systems level. Elsewhere, Thornton and I have 
argued that engagement in a PLC demands "deeper, more intensive PL over a longer timeframe than that which has traditionally been available to the sector" (Cherrington \& Thornton, 2015, p. 326). In order to develop PLCs, Thornton and Wansbrough (2012) suggest the following factors need addressing:

...the crucial role of the professional leader ... opportunities for feedback and coaching and mentoring ... strengthening of relationships with family/whānau in order to support children's learning ... embed[ding] change into the culture of the service ... prioritising time for shared reflection and meaningful conversations around learning and teaching. (p. 58)

Addressing these factors and developing sustainable PLCs at the local level requires commitment from ECE service management to resource PLD adequately, particularly in terms of structural supports such as paid meeting time, creation of meaningful PLD budgets that enable provision of external support especially during PLC development stages, and recognising the diversity of background experiences and qualifications staff are likely to bring to the team. It also requires that teachers take greater control of their own professional learning and their commitment to a critical team culture that encourages debate, supports critical reflection on their own and others' practices, welcomes different perspectives, and focuses on learning success for all children. Maintaining an evaluative stance towards their own PLD engagement, including asking Earley and Porritt's (2009, p. 8) “impact evaluation" questions - "What have we achieved (as a result of engaging in CPD activity) that is making a difference to the practice of the staff, the [ECE service] and to the learning of the children?" and "What evidence is telling us that we are making this difference?" - contribute to such a culture.

Even with such commitment, the development of effective, sustainable PLCs as the norm across ECE is unlikely to be achieved without increased support at a systems level, given evidence from the ERO national reports that several areas of practice, including self-review, require strengthening in order to build quality across the sector (e.g., ERO, 2009, 2010). Whilst much of the MOE's current PLD contracts are targeted at services identified by ERO reviews as "not well placed" (p. 47) or "requires further development" (p. 47) in order to "promote positive learning outcomes for children" (ERO, 2014, p. 47), the delivery of short-term PLD programmes is unlikely to be sufficient to develop the critical culture or professional skills characteristic of a PLC. Rather, expansion of the COL | Kāhui Ako approach to PLD to enable greater take-up by EC services is necessary. Restoring funding levels to those in place prior to 2010 would also enable EC services to adequately resource provision of PLD for their staff, particularly those without access to either MOE-funded or COL |Kāhui Ako programmes. The Government's 2016 Better Public Service target that "98\% of children starting school will have participated in quality ECE" is built on the premise that "taking part in quality learning builds a strong foundation for children's ongoing education" (MOE, 2016b). To achieve such quality requires policy commitment towards the provision of effective PLD across the EC sector, alongside that available in the schooling sector.

\section{References}

Avalos, B. (2011). Teacher professional development in Teaching and Teacher Education over ten years. Teaching and Teacher Education, 27, 10-20. 
Barber, H., Cohrssen, C., \& Church, A. (2014). Meeting the Australian National Quality Standards: A case study of the professional learning needs of early childhood educators. Australasian Journal of Early Childhood, 39(4), 21-27.

Borko, H. (2004). Professional development and teacher learning: Mapping the terrain. Educational Researcher, 33(8), 3-15.

Borko, H., Jacobs, J., \& Koellner, K. (2010). Contemporary approaches to teacher professional development. In P. Peterson, E. Baker, \& B. McGaw (Eds.), International encyclopedia of education (Vol. 7, pp. 548-556). Oxford, England: Elsevier.

Brownlee, J. L., Sumision, J., Irvine, S., Berthelson, D., Farrell, A., Walsh, K., Ryan, S., \& Mulhearn, G. (2015). Taking an evaluative stance to decision-making about professional development in early childhood education and care. Early Years, 35(4), 411-426.

Cherrington, S., \& Thornton, K. (2015). The nature of professional learning communities in New Zealand early childhood education: An exploratory study. Professional Development in Education, 41(2), 310-328.

Cherrington, S., \& Wansbrough, D. (2007). National evaluation of early childhood education professional development. Wellington: Ministry of Education.

Dana, N. F., \& Yendol-Hoppey, D. (2008). The reflective educator's guide to professional development: Coaching inquiry-oriented learning communities. Thousand Oaks, CA: Corwin Press.

DuFour, R., \& Eaker, R. (1998). Professional learning communities at work: Best practices for enhancing student achievement. Bloomington, IN: National Educational Service.

Earl, L., \& Timperley, H. (2008). Understanding how evidence and learning conversations work. In L. Earl \& H. Timperley (Eds.), Professional learning conversations: Challenges in using evidence for improvement (pp. 1-12). Dordretch: Springer.

Earley, P., \& Porritt, V. (Eds.). (2009). Effective practices in continuing professional development: Lessons from schools. London: Institute of Education.

Education Council New Zealand. (2016). Practising teacher criteria. Retrieved from https://educationcouncil.org.nz/sites/default/files/Practising\%20teacher\%20criteria\% 20English.pdf

Education Council New Zealand. (2017). Our code, our standards: Draft code of professional responsibility and standards for the teaching profession. Retrieved from https://educationcouncil.org.nz/sites/default/files/Our\%20Code\%200ur\%20Standards .pdf

Education Counts. (2017a). Early childhood education staffing statistics. Retrieved from https://www.educationcounts.govt.nz/statistics/early-childhood-education/staffing

Education Counts. (2017b). Early childhood education services statistics. Retrieved from https://www.educationcounts.govt.nz/statistics/early-childhood-education/services

Education Review Office. (2009). Implementing self-review in early childhood services. Wellington, NZ: Author.

Education Review Office. (2010). Quality in early childhood services. Retrieved from http://www.ero.govt.nz/publications/quality-in-early-childhood-services/

Education Review Office. (2014). He Pou Tãtaki: How ERO reviews early childhood services. Retrieved from http://www.ero.govt.nz/assets/Uploads/He-Pou-Tataki-July-2014.pdf

Education Review Office. (2016). Early learning curriculum: What's important and what works. Wellington, NZ: Author.

Edwards, S., \& Nuttall, J. (2009). Introduction. In S. Edwards \& J. Nuttall (Eds.), Professional learning in early childhood settings (pp. 1-8). Rotterdam: Sense. 
Ermeling, B. A. (2010). Tracing the effect of teacher inquiry on classroom practice. Teaching and Teacher Education, 26, 377-388.

Gomez, R. E., Kagan, S. L., \& Fox, E. A. (2015). Professional development of the early childhood education teaching workforce in the United States: An overview. Early Years, 41(2), 169-186.

Greeno, J, (1997). On claims that answer the wrong questions. Educational Researcher, 26(1), 5-17.

Greeno, J., \& The Middle School Through Applications Project Group. (1998). The situativity of knowing, learning, and research. American Psychologist, 53(1), 5-26.

Grossman, P., Wineburg, S., \& Woolworth, S. (2001). Toward a theory of teacher community. Teachers College Record, 103(6), 942-1012.

Guskey, T. (2000). Evaluating professional development. Thousand Oaks, CA: Corwin Press.

Hipp, K. K., \& Huffman, J. B. (Eds.). (2010). Demystifying professional learning communities: School leadership at its best. Lanham, MD: Rowman \& Littlefield Education.

Hipp, K. K., Huffman, J. B., Pankake, A. M., \& Olivier, D. F. (2008). Sustaining professional learning communities: Case studies. Journal of Educational Change, 9, 173-195.

Horn, I., \& Little, J. (2010). Attending to problems of practice: Routines and resources for professional learning in teachers' workplace interactions. American Educational Research Journal, 47(1), 181-217.

Kintz, T., Lane, J., Gotwals, A., \& Cisterna, D. (2015). Professional development at the local level: Necessary and sufficient conditions for critical colleagueship. Teaching and Teacher Education, 51, 121-136.

Lave, J., \& Wenger, E. (1991). Situated learning: Legitimate peripheral participation. Cambridge: Cambridge University Press.

McLaughlin, M., \& Talbert, J. (2006). Building school-based teacher learning communities: Professional strategies to improve student achievement. New York: Teachers College Press.

Ministry of Education. (2008a). Education (early childhood services) regulations. Retrieved from

http://www.legislation.govt.nz/regulation/public/2008/0204/latest/DLM1412501.htm I?search=ts_regulation_early+childhood_resel\&sr=1

Ministry of Education. (2008b). Licensing criteria for centre-based ECE services. Retrieved from http://www.education.govt.nz/early-childhood/running-an-ece-service/theregulatory-framework-for-ece/licensing-criteria/centre-based-ece-services/

Ministry of Education Professional Development Advisory Group. (2014). Report of the professional development advisory group. Retrieved from file://C:/Users/cherrisu.STAFF/Downloads/PLDAdvisoryGroupReport\%20(2).pdf

Ministry of Education. (1996). Te Whāriki: Early childhood curriculum. Wellington: Learning Media.

Ministry of Education. (1999). The quality journey. Wellington: Learning Media.

Ministry of Education. (2002). Nga huarahi arataki: Pathways to the future. A 10-year strategic plan for early childhood education. Wellington: Learning Media.

Ministry of Education. (2004). Kei tua o te pae Assessment for learning: Early childhood exemplars: Books 1-9. Wellington: Learning Media.

Ministry of Education. (2006). Ngā arohaehae whai hua: Self-review guidelines for early childhood education. Wellington: Learning Media. 
Ministry of Education. (2007). Request for proposals for Te Whāriki professional development. Wellington: Author.

Ministry of Education. (2009). Kei tua o te pae Assessment for learning: Early childhood exemplars: Books 10-20. Wellington: Learning Media.

Ministry of Education. (2010). Request for proposals for early childhood education professional development programmes July 2010 - June 2013. Wellington: Author.

Ministry of Education. (2016a). Investing in educational success. Retrieved from http://www.education.govt.nz/ministry-of-education/specific-initiatives/investing-ineducational-success

Ministry of Education. (2016b). Better public service targets: More children in early childhood education. Retrieved from http://www.education.govt.nz/ministry-ofeducation/government-education-initiatives/better-public-services/more-children-inearly-childhood-education/

Ministry of Education. (2016c). Final report of the ECAC Communities of Learning sub-group. Wellington: Author.

Ministry of Education. (2017a). Strengthening early learning opportunities. Retrieved from http://www.education.govt.nz/early-childhood/running-an-ece-service/employingece-staff/selo/

Ministry of Education. (2017b). Information on Te Whāriki 2017. Retrieved from https://education.govt.nz/early-childhood/teaching-and-learning/ece-curriculum/tewhariki/

Ministry of Education. (2017c). Communities of learning: Kāhui Ako. Retrieved from https://education.govt.nz/communities-of-learning/

Mitchell, L., \& Cubey, P. (2003). Characteristics of professional development linked to enhanced pedagogy and children's learning in early childhood settings: Best evidence synthesis. Wellington: NZ Ministry of Education.

NZEI Te Riu Roa. (2016). Early childhood education post budget survey: How a six-year funding freeze is impacting on ECE. Wellington, NZ: Author.

Newman, L., \& Mowbray, S. (2012). 'We were expected to be equal': Teachers and academics sharing professional learning through practitioner inquiry. Teachers and Teaching: Theory and Practice, 18(4), 455-468.

Opfer, V. D., \& Pedder, D. (2011). Conceptualising teacher professional learning. Review of Educational Research, 81(3), 376-407.

Owen, S. M. (2015). Teacher professional learning communities in innovative contexts: 'Ah hah moments', 'passion' and 'making a difference' for student learning. Professional Development in Education, 41(1), 57-74.

Stoll, L., \& Louis, K. S. (Eds.). (2007). Professional learning communities: Divergence, depth and dilemmas. Maidenhead: McGraw-Hill/Open University Press.

Stoll, L., Bolam, R., McMahon, A., Wallace, M., \& Thomas, S. (2006). Professional learning communities: A review of the literature. Journal of Educational Change, 7, 221-258.

Thornton, K., \& Cherrington, S. (2014). Leadership in professional learning communities. Australasian Journal of Early Childhood, 39(3), 94-102.

Thornton, K., \& Wansbrough, D. (2012). Professional learning communities in early childhood education. Journal of Educational Leadership, Policy and Practice, 27(2), 51-64.

Waters, J., \& Payler, J. (2015). The professional development of early years educators: Achieving systematic, sustainable and transformative change. Early Years, 41(2), 161168. 
Sue Cherrington is the Associate Dean (Academic) in the Faculty of Education. Sue's over-arching research focus is on professional and pedagogical practices in ECE, including teacher thinking and reflection, teacher professional learning and development, teachers' ethical and professional experiences and practices, and teachers' professional and pedagogical responses to working with diverse children and families. More recently, Sue has extended her research interests into the tertiary education field with research projects into the development of professional learning community within a higher education context and into students' transition from secondary school to university.

Email: sue.cherrington@vuw.ac.nz 